\title{
VIBRATION ANALYSIS OF A RESIDENTIAL BUILDING
}

\author{
Regina Augusta Sampaio,a and Remo Magalhâes de Souza ${ }^{2}$ \\ ${ }^{1}$ Federal University of Pará, Department of Civil Engineering, 66075-110, Augusto Correa St, 01, Pará, Brazil \\ ${ }^{2}$ Núcleo de Instrumentação e Computação Aplicada à Engenharia, Universidade Federal do Pará, Pará, Brazil
}

\begin{abstract}
The aim of this paper is to present the results of a study regarding vibration problems in a 17 storey residential building during pile driving in its vicinity. The structural design of the building was checked according to the Brazilian standards NBR6118 and NBR6123, and using commercial finite element software. An experimental analysis was also carried out using low frequency piezo-accelerometers attached to the building structure. Structure vibrations were recorded under ambient conditions. Four monitoring tests were performed on different days. The objective of the first monitoring test was an experimental modal analysis. To obtain de modal parameters, data was processed in the commercial software ARTEMIS employing two methods: the Stochastic Subspace Identification and the Frequency Domain Decomposition. Human comfort was investigated considering the International Standard ISO 2631. The Portuguese standard, NP2074, was also used as a reference, since it aims to limit the adverse effects of vibrations in structures caused by pile driving in the vicinity of the structure. The carried out experimental tests have shown that, according to ISO2301, the measure vibration levels are above the acceptance limits. However, velocity peaks are below the limits established by NP2074. It was concluded that, although the structure has adequate capacity to resist internal forces according to normative criteria, it has low horizontal stiffness, which could be verified by observing the vibration frequencies and mode shapes obtained with the finite element models, and its similarity with the experimental results. Thus, the analyses indicate the occurrence of discomfort by the residents.
\end{abstract}

\section{Introduction}

This paper presents the results of a vibration analysis in a 17 storey residential building located in the city of Belem, northern Brazil. Residents reported the occurrence of vibrations in the building during pile driving in the vicinity, resulting on falling objects, small cracks and discomfort to people.

Thus, seeking to investigate the level of structural safety of the building, a computer analysis was performed to verify if the building was correctly designed according to Brazilian standards. In addition, in order to evaluate the comfort level of residents a comfort analysis was performed considering international standards.

The dynamic effect of wind was considered acoording to the Brazilian standard NBR 6123[1], which reads: "In buildings with fundamental period T equal to or less than Is (i.e. frequency greater than $1 \mathrm{~Hz}$ ), the influence of fluctuating response due to wind is small and its effects are already considered in determining the time interval adopted for the factor that depends on the surface roughness and the dimensions of the building. However, buildings with fundamental period greater than $1 s$, particularly those weakly damped, may present important fluctuating response in the mean wind direction. The total dynamic response, equal to the superposition of the mean and fluctuating response, can be calculated according to the specifications of the standard". As a general rule, the maximum amplitude of acceleration may not exceed 0.1 $\mathrm{m} / \mathrm{s} 2$.

Another Brazilian standard, NBR6118 [2], defines the limit of excessive vibration (ELS-EV) as the condition in which the vibrations reach the limits established for the normal use of the building. This condition must be verified considering a frequent combination .

Issues concerning the specification of standard limits of comfort values are quite delicate because of the complexity on the phenomenon of vibrations and also the human response to vibration which is influenced by cultural and social factors of users. This fact can be verified by observing international standard recommendations on the subject [3], [4], [5] and [6]. According to ISO 2631-2 [3] (version of 2003), in many circumstances, the level of discomfort and complaint of the users cannot be explained directly and only by the magnitude of the vibrations measured. Analysis of these complaints has shown that other parameters related to the vibration source or the result of vibration (noise) influence the discomfort of users. Therefore, to evaluate the level of comfort, several factors must be taken into account. However, it is known that, in general, the human has a greater sensitivity to vibrations at frequencies less than $10 \mathrm{~Hz}$

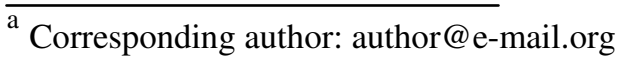




\section{Computational Analysis}

The structural system of the building is a reinforced concrete spatial frame with waffle slabs. The building foundations consisted of root piles. The wind forces were considered based on the Brazilian standard NBR 6123 [1], and the basic wind velocity was $30 \mathrm{~m} / \mathrm{s}$. The critical damping used was $2 \%$.

The spatial frame of the building has a very low fundamental frequency, around $0.2 \mathrm{~Hz}$ (period of $5 \mathrm{~s}$ ). According to NBR 6123 [1], a building with a period longer than $1 \mathrm{~s}$ may present important fluctuating response in the mean wind direction. This is evident when one checks the maximum accelerations due to design wind forces.

From Table 1 one observes that, in the load cases 5 and 6 (wind direction 90 and 270 degrees) the maximum acceleration values $(0.202 \mathrm{~m} / \mathrm{s} 2)$ correspond approximately to twice the Brazilian standard limit value $(0.1 \mathrm{~m} / \mathrm{s} 2)$, and according to the limit ranges suggested by CEB Bulletin 209 [4], it is considered "Clearly Perceptible".

This happens because the structure does not present sufficient horizontal stiffness, which is evidenced by the low natural frequencies observed (first theoretical natural frequency of the building about $0.2 \mathrm{~Hz}$ ).

Table 1. Human perceptibility to vibration in buildings in relation to the wind

\begin{tabular}{|c|c|c|c|}
\hline $\begin{array}{c}\text { Load } \\
\text { case }\end{array}$ & $\begin{array}{c}\text { Acceleration } \\
\mathrm{X}\left(\mathrm{m} / \mathrm{s}^{2}\right)\end{array}$ & $\begin{array}{c}\text { Acceleration } \\
\mathrm{Y}\left(\mathrm{m} / \mathrm{s}^{2}\right)\end{array}$ & $\begin{array}{c}\text { Human } \\
\text { response }\end{array}$ \\
\hline 5 & 0.022 & 0.202 & $\begin{array}{c}\text { Cleary } \\
\text { perceptible }\end{array}$ \\
\hline 6 & 0.022 & 0.202 & $\begin{array}{c}\text { Cleary } \\
\text { perceptible }\end{array}$ \\
\hline 7 & 0.046 & 0.031 & Imperceptible \\
\hline 8 & 0.046 & 0.031 & Imperceptible \\
\hline
\end{tabular}

The building vibration modes corresponding to the first three natural frequencies are shown in Figure 1

NBR6123 [1] provides an equation for calculating the fundamental period for "framed reinforced concrete structures, without curtains" and it is given by

$$
\mathrm{T}=0,05+0,015 \mathrm{~h}
$$

where $\mathrm{h}$ corresponds to the building height in meters. Using this formula, considering the building dimensions, i.e, for $\mathrm{h}=55,82 \mathrm{~m}$, the following values are obtainted, respectively, for period and frequency: $\mathrm{T}=0.887 \mathrm{~s}$ and $\mathrm{f}=$ $1.127 \mathrm{~Hz}$. In other words, by assuming that the results of this formula as being average values for this type of structure, it can be concluded that the values for the fundamental building frequencies are very low.

Regarding the frequency of vertical vibration of the floors, NBR 6118 [2] also presents critical values for natural frequencies. However, it does not mention residential buildings. Considering the most similar case as possible, i.e., offices, critical frequencies are between
3.0 to $4.0 \mathrm{~Hz}$. According to NBR 6118 [2], the natural frequency must be higher than 1.2 times the critical frequency. As the first vertical vibration frequency of the floor is $6.5 \mathrm{~Hz}$, this criterion is satisfied for office buildings.

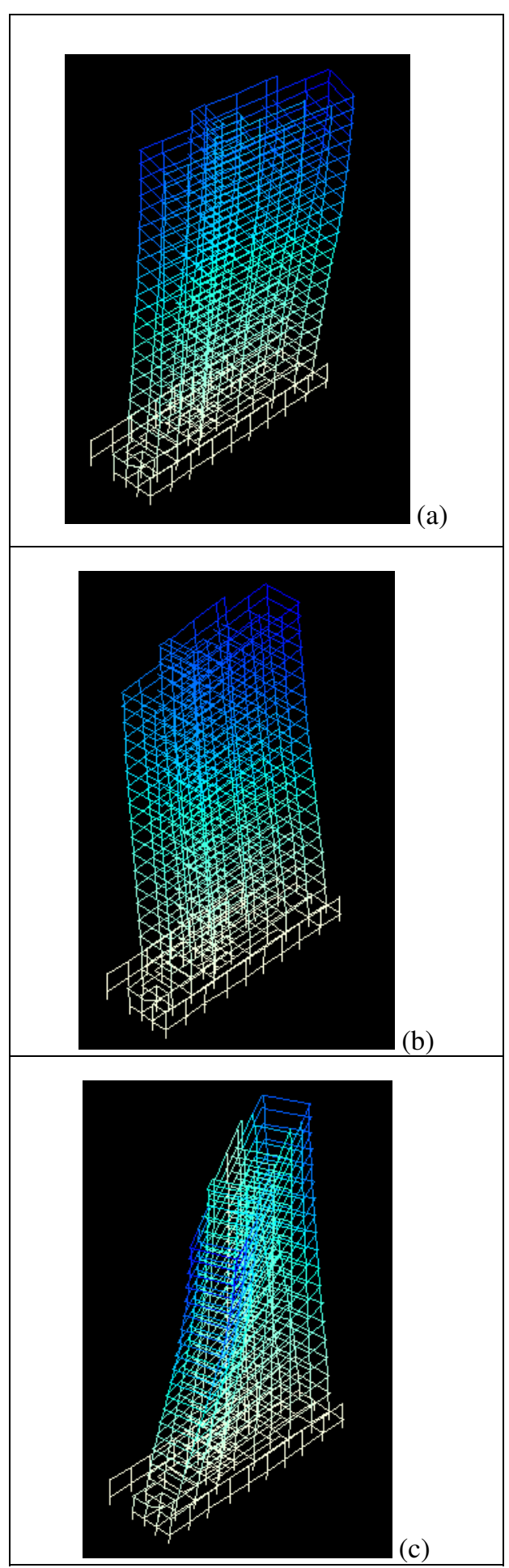

Figure 1. Global mode shapes of the building. (a) First mode shape, bending on $\mathrm{x}$ direction (longitudinal), $\mathrm{f}=0.199 \mathrm{~Hz}$; (b) Second mode shape - bending on y direction (transversal), $\mathrm{f}=0.235 \mathrm{~Hz}$; (c) Third mode shape- torsion, $\mathrm{f}=0.272 \mathrm{~Hz}$. 
The vertical vibration mode shapes of the floors, with an indication of their natural frequencies are shown in Figure 2.

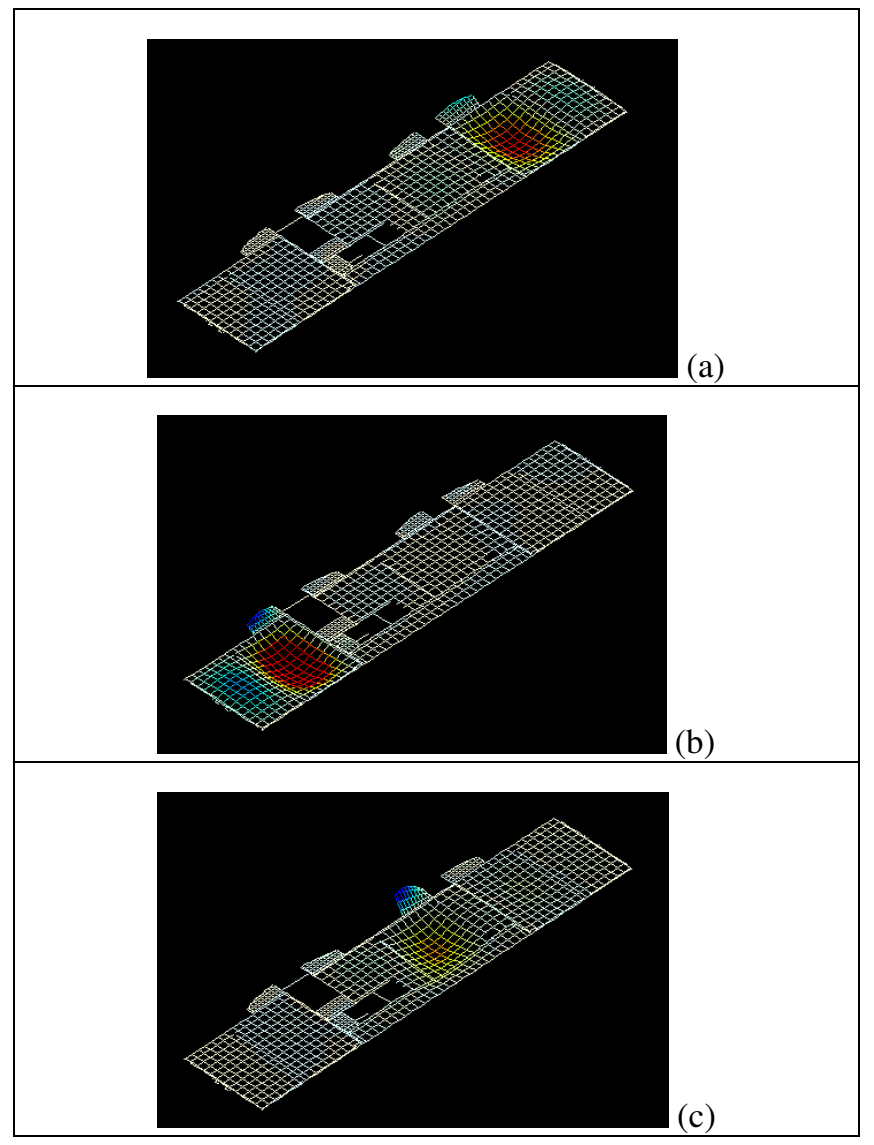

Figure 2. (a) - First mode shape of the typical floor. ( $\mathrm{f}=6.5 \mathrm{~Hz})$. (b) - Second mode shape of the typical floor. $(\mathrm{f}=6.8 \mathrm{~Hz})$. (c) Third mode shape of the typical floor. $(\mathrm{f}=7.5 \mathrm{~Hz})$

\section{Experimental Dynamic tests}

To perform dynamic tests, accelerometers were fixed to the building structure according to four different settings. Structure vibrations were recorded under ambient conditions such as rain, winds, vehicular traffic on the garage and pile driving in the vicinity of the building

The acceleration spectra corresponding to the maximum measured values are compared with the vibration limit curves of ISO 2631-2 [5] (version of 1989) multiplied by factors that vary according to type of building. Thus, the base curves were multiplied by factors 2 to 4 , which correspond to residential buildings with intermittent vibrations, considering daytime. Figure 8 shows a scheme of the procedure for assessment of comfort according to the acceptance criteria of ISO $2631[5]$.

The vibrations in structural elements of the first storey (which are directly connected to the building foundation) were also monitored. The Portuguese standard NP 2074 [7] aims to limit the damaging effects caused by vibrations in structures in the vicinity of excavations with explosives, pile driving, or others of the same characteristics. This standard establishes the limit value for the peak velocity using three factors. These factors contemplate the type of construction, type of soil and daily frequency of load occurrence, differing from most other international standards. Recently, a review of NP 2074 [7] suggested the limits of Table 9, which depend on the type of structure and on the predominant frequencies in the spectrum.

In the case under study, the structure is classified as current and the dominant frequency is lower than $10 \mathrm{~Hz}$. Thus, the limit for peak velocity is $5 \mathrm{~mm} / \mathrm{s}$.

Table 2. Base curve's multiplying factors. Source: ISO 26312,1989 [5].

\begin{tabular}{|c|c|c|c|}
\hline Place & Time & $\begin{array}{c}\text { Continuous or } \\
\text { intermittent } \\
\text { vibration }\end{array}$ & $\begin{array}{c}\text { Transient } \\
\text { vibration }\end{array}$ \\
\hline \multirow{2}{*}{$\begin{array}{c}\text { Residential } \\
\text { building }\end{array}$} & daytime & $2 \mathrm{a} 4$ & 30 to 90 \\
\cline { 2 - 4 } & night & 1.4 & 1.4 to 20 \\
\hline
\end{tabular}

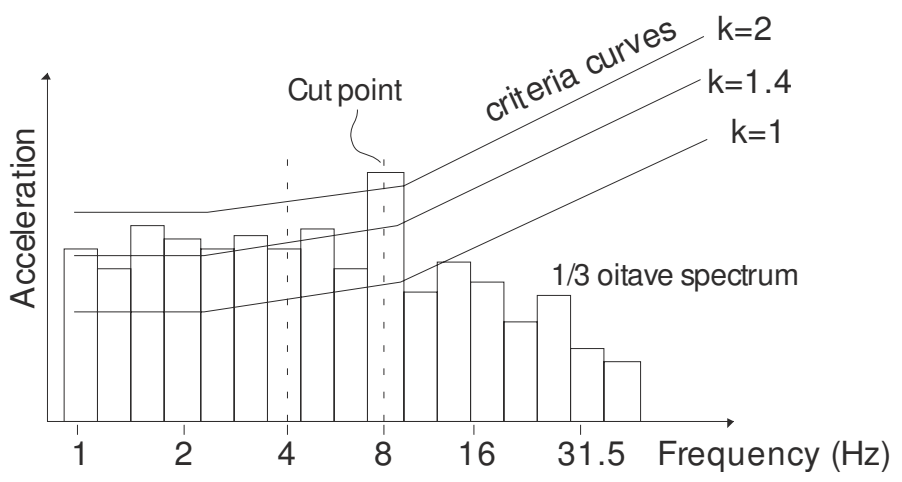

Figure 3. Scheme of the procedure for assessment of comfort according to the acceptance criteria of ISO 2631[5]

Table 3. Revision proposed for NP 2074, peak velocity in $\mathrm{mm} / \mathrm{s}$ of the vibration measured in a structural element linked to the foundation [7].

\begin{tabular}{|c|c|c|c|}
\hline \multicolumn{4}{|c|}{ Peak velocity - v $\left(\mathrm{mm}^{-} \mathrm{s}^{-1}\right)$} \\
\hline \multirow{2}{*}{$\begin{array}{c}\text { Type of } \\
\text { structure }\end{array}$} & \multicolumn{3}{|c|}{ Dominant frequency } \\
\cline { 2 - 4 } & $\mathrm{f} \leq 10 \mathrm{~Hz}$ & $10<\mathrm{f} \leq 50 \mathrm{~Hz}$ & $\mathrm{f}>50 \mathrm{~Hz}$ \\
\hline sensible & 2.5 & 5 & 10 \\
\hline current & 5 & 10 & 20 \\
\hline reinforced $*$ & 15 & 30 & 60 \\
\hline
\end{tabular}

\subsection{Monitoring Program}

Four monitoring tests were carried out on different days, in the period between February 6th and April 03rd, 2012. 
The monitoring tests were carried out according to Table 4.

The first test was conducted to evaluate the global dynamic behavior of the building thereby determining its global natural frequencies and mode shapes. Modal analysis of 11th floor slabs was also performed in test 2 . The peak velocity of columns vibration near the foundation, on ground floor, was checked in tests 1 and 4 . Comfort analysis according to ISO 2301 was performed based on tests 2 and 3 .

Table 4. Tests descriptions.

\begin{tabular}{|c|c|c|c|}
\hline Test & $\begin{array}{c}\text { Number } \\
\text { of Accel. }\end{array}$ & Description & Notes \\
\hline 1 & 27 & $\begin{array}{c}\text { Columns on } \\
\text { ground floor, } \\
\text { 4th, 10th, 14th, } \\
\text { 16th floors }\end{array}$ & $\begin{array}{c}\text { Pile driving } \\
\text { and ambient } \\
\text { vibration }\end{array}$ \\
\hline 2 & 10 & $\begin{array}{c}\text { Six slabs on 11th } \\
\text { floor }\end{array}$ & $\begin{array}{c}\text { Pile driving } \\
\text { and ambient } \\
\text { vibration }\end{array}$ \\
\hline 3 & 6 & $\begin{array}{c}\text { Two slabs on 1st } \\
\text { floor }\end{array}$ & $\begin{array}{c}\text { Online } \\
\text { monitoring } 24 \\
\text { hs per day - 6 } \\
\text { days }\end{array}$ \\
\hline 4 & 15 & $\begin{array}{c}\text { Columns on } \\
\text { Ground floor }\end{array}$ & $\begin{array}{c}\text { Ambiente } \\
\text { vibration, }\end{array}$ \\
\hline
\end{tabular}

The first test was conducted to evaluate the global dynamic behavior of the building thereby determining its global natural frequencies and mode shapes. Modal analysis of 11th floor slabs was also performed in test 2 . The peak velocity of columns vibration near the foundation, on ground floor, was checked in tests 1 and 4. Comfort analysis according to ISO 2301 was performed based on tests 2 and 3 .

The monitoring tests were performed with low frequency accelerometers Wilcoxon ${ }^{\circledR}$ 793L (http://www.wilcoxon.com/vi_index.cfm?PD_ID=11)

with nominal sensitivity of $500 \mathrm{mV} / \mathrm{g}$ connected to a Lynx ${ }^{\circledR}$ ADS-2000 data acquisition system with 16 channels (Figure 4). These acceleration data were analysed using the software AqDados [8], specifically for data acquisition and analysis. The accelerometers were mounted on metallic base plates attached to the columns or slabs with high strength adhesive.

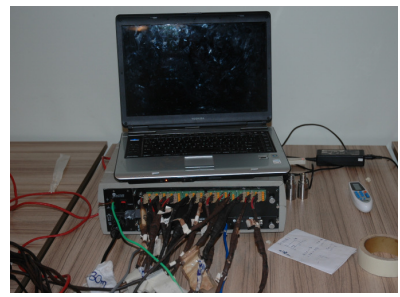

(a)

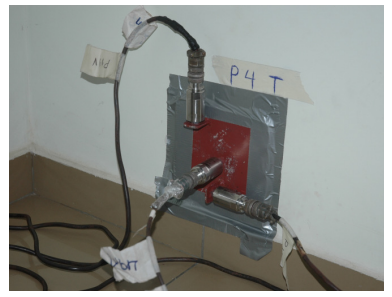

(b)
Figure 4. (a) - acquisition system positioned on the ground floor - monitoring test I;(b) accelerometers in column P4 on the ground floor - monitoring test I.

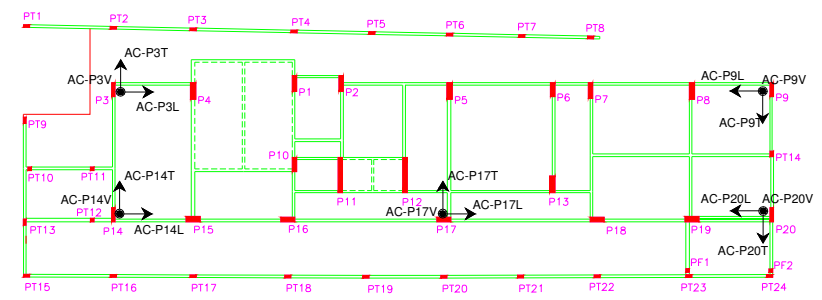

(a)

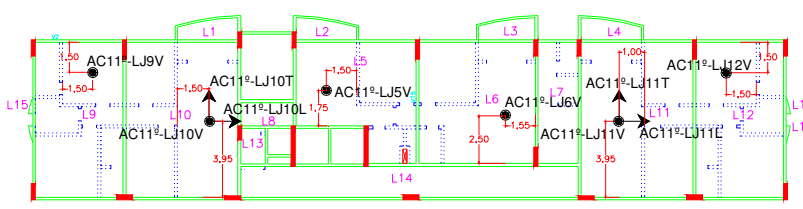

(b)

Figure 5. Accelerometers deployment: (a) test 1 and (b) test 2.

\subsection{Experimental modal analysis}

The experimental modal analysis was carried out with commercial software, ARTEMIS [9], employing two methods: the stochastic subspace identification (SSI) and the frequency domain decomposition (EFDD). The obtained global natural frequencies are shown in Table 5 and the mode shapes corresponding to the natural frequencies $3.67 \mathrm{~Hz}$ and $7.9 \mathrm{~Hz}$ are shown in Figure 6 and Figure 7, respectively.

Table 5. Global natural frequencies - experimental analysis

\begin{tabular}{|c|c|c|c|c|c|c|c|}
\hline $\begin{array}{c}\text { Freq. } \\
(\mathrm{Hz})\end{array}$ & 0,78 & 3,67 & 7,90 & 17,3 & 23,5 & 30,5 & 57,8 \\
\hline
\end{tabular}

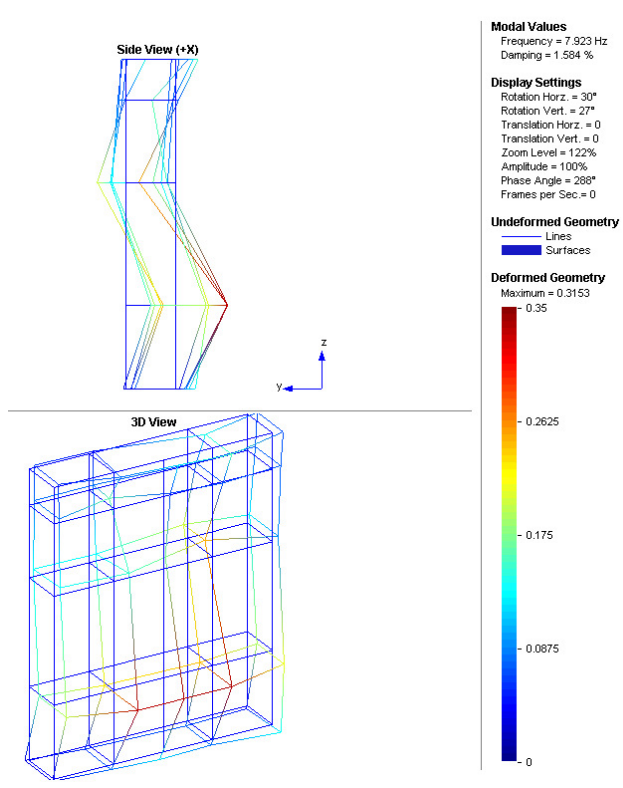

Figure 6. Mode shape of frequency $3.67 \mathrm{~Hz}$ 


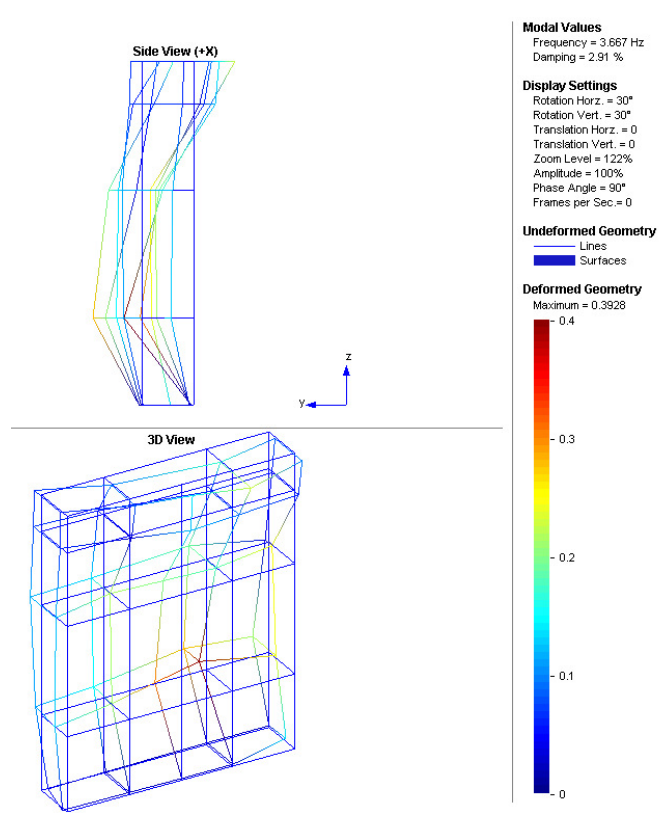

Figure 7. Mode shape of frequency $7.9 \mathrm{~Hz}$

Experimental modal analysis to determine the natural frequencies of vibration of the 11th floor was also performed. The natural frequencies found for this test are shown in Table 6.

Table 6. Natural frequencies of the 11th floor

\begin{tabular}{|c|c|c|c|c|c|}
\hline $\begin{array}{c}\text { Freq. } \\
(\mathrm{Hz})\end{array}$ & 8.04 & 31.76 & 37.16 & 55.65 & 59.8 \\
\hline
\end{tabular}

\subsection{Human Comfort Analysis}

The acceleration spectra were calculated to assess human comfort from the measured acceleration time histories. These spectra were determined considering the records of accelerations with greater peak to peak amplitude from all the measured time series.

It was observed that for the 11th floor, in all cases the limits established by the standard are met, i.e., the vibration level is acceptable according to the type of vibration, duration and area of occupation of the building. In test 3 , the 1 st floor was monitored and Figure 8 shows one of the acceleration spectrum of the slabs in the $y$ direction, corresponding to the maximum measured value. The bars indicate the maximum average squared values of monitored accelerations. In directions $\mathrm{x}$ and $\mathrm{z}$, the acceleration levels remain below the limits established by ISO 2631-2 [5]. However, in the $y$ direction (Figure 8), the acceleration spectrum exceeds the recommended values for this case, which must be between the curves with coefficients 2 and 4

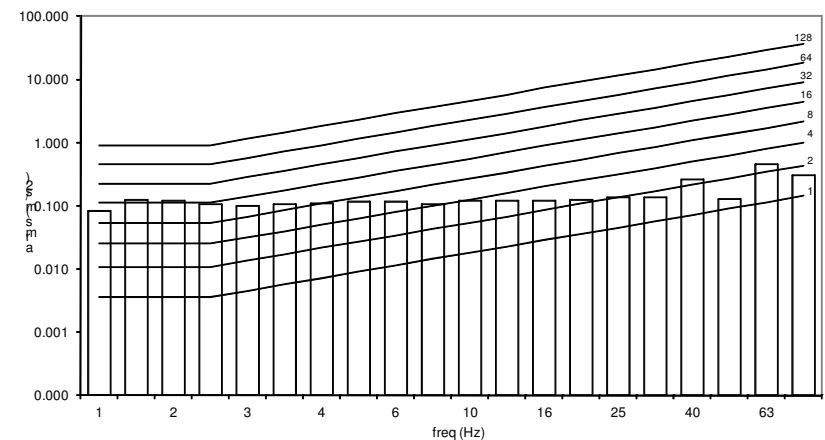

Figure 8. Acceleration spectrum, the y direction (transversal) test 3 - 1st floor

\subsection{Peak Velocity Limit}

The acceleration time histories were integrated to obtain velocity time histories to determine the maximum velocity achieved during tests.

The maximum velocity found in columns of the ground floor was $3.6 \mathrm{~mm} / \mathrm{s}$ in test 1 and $3.2 \mathrm{~mm} / \mathrm{s}$ in the test 4 . These velocity values are below the limit recommended by the review of the NP2074 standard, as mentioned above (Table 3).

\section{Conclusion}

The feeling of vibrating in the building reported by residents is compatible with the studies.

It can be said that the structure has adequate bearing capacity to resist internal forces related to the Brazilian normative criteria. However, the structure has a low horizontal rigidity, which can be checked observing the vibration frequency obtained by numerical modelling, and consistent with the results obtained experimentally.

Thus, the analyses indicated the occurrence of discomfort by the residents, which can be remedied by increasing the horizontal stiffness of the building.

Regarding the records of accelerations of the 1st floor slabs of the building under study, the experimental analysis have shown that, according to ISO 2631, the measured vibration levels are above the limits of acceptability. On the other hand, the velocity peaks in structural elements connected to the foundations are below the limits of the Portuguese standard, NP 2074. Thus, under this criterion, the structure is safe.

\section{Acknowledgments}

Authors gratefully acknowledge the following field team members: Eduardo Tagliarini, Ariany Silva, Marilene Cardoso, André Felipe Queiroz, and Edilson Morais Lima e Silva for their cooperation and help during the tests. 


\section{References}

1. ASSOCIAÇÃO BRASILEIRA DE NORMAS TÉCNICAS. NBR6123: Forças devidas ao vento em edificações. ABNT. Rio de Janeiro, 84 p., 1987.

2. ASSOCIAÇÃO BRASILEIRA DE NORMAS TÉCNICAS. NBR6118: Projeto de Estruturas de concreto - Procedimento. ABNT. Rio de Janeiro, 170 p., 2003.

3. ISO 2631-2 (2003). Mechanical vibration and shock -- Evaluation of human exposure to whole-body vibration -- Part 2: Vibration in buildings (1 $\mathrm{Hz}$ to $80 \mathrm{~Hz}$ ). Second Edition. Geneve: International Organization for Standardization.

4. CEB. Comité Euro-International du Béton, Bulletin d'Information 209, Vibration Problems in Structures: practical guidelines. Lausanne, Switzerland, Aug. 1991.

5. ISO 2631/2 (1989). Evaluation of human exposure to whole body vibration - Part 2: continuous and shock-induced vibration in buildings (1 to $80 \mathrm{~Hz}$ ). First Edition. Geneve: International Organization for Standardization.

6. ISO 2631/1 (1997). Mechanical Vibration and Shock - Evaluation of Human Exposure to Whole Body Vibration - Part 1: General Requirements. Second Edition. Geneve: International Organization for Standardization.

7. NP 2074 (1983). "Avaliação da influência em construções de vibrações provocadas por explosões ou solicitações similares". Instituto Português da Qualidade (IPQ), Lisboa

8. AqDados 7.0. Acquisition data software. Lynx Tecnologia Eletrônica Ltda. User manual. 2003.

9. Structural Vibration Solution A/S, ARTeMIS Modal 3.0, NOVI Science Park, Niels Jernes Vej 10, DK-9220 Aalborg East, Denmark; www.svibs.com 